\title{
A Smart System for Women Security: A New Innovation in the Domain of Women Security
}

\author{
Ajay Giri \\ VES Institute of Technology \\ Chembur, Mumbai, India
}

\author{
Sangita Oswal \\ VES Institute of Technology \\ Chembur, Mumbai, India
}

\begin{abstract}
In INDIA, Women Security issues has been on fire these days. In spite of having many women security laws, security device, mobile phone apps, the concern remains the same. There are many SMART phone's apps available in the market which cater to this issue but the basic problem with these apps been, all will work only when the phone is not Switchoff . In this paper we propose a model SMART SYSTEM which takes care of the worst situation namely the phone is switched off or battery has been taken out or thrown by criminals. SMART SYSTEM will have voice recognition system in place which will generate a trigger to activate system function, if the voice pattern is matched. The system will send message with a 30 seconds recorded voice to group of specified user who can help the user immediately as well as to nearest police and also to higher authority of police.
\end{abstract}

\section{Keyword}

Security, SMART APP, Voice Recognition, SMART phone

\section{INTRODUCTION}

India is one of the unsafe country for women Security as a evidenced by shocking rates of so many cases which has happened in India i.e. shocking rates of abusing ,hitting, kicking, burning and rape. According to latest estimates by Government of India, One Women is raped every 22 minutes in India. According to the National Crime Records Bureau, 24,206 rape cases were registered in India in 2011 and 24923 cases in 2012.These figures emphasises that even though there is sufficient amount of growth in Technology but still women in India are not Safe. In the most the cases rape Victim knows their attacker. In $98 \%$ cases victim know their attacker or we can say attacker is none other than victims friends, relatives etc. In India there are many Laws been made consistently over the period of time as and when needed, but still cases are increasing every year. Besides this there are many IT inventions Smart phone apps for preventing these kind of behaviour towards women few been listed are GoSuraksheit, FightBack, Telltail, Circle of 6,Hollaback,but after having analyzed all these APPS it is noted that it fail at certain point of time. Consider a scenario where attacker snatched out phone from victim and they/he switched off the phone or they/he thrown out the battery of phone or they take out the SIM card from phone then the system fails. In such a situation these APPS will not work. These issues are been considered to design the model SMART SYSTEM for Women Security. SMART SYSTEM, means it will work even when phone is switched off or SIM is taken out from Phone.

Now a days Government of India is also taking so many Initiatives for Women Security in all terms i.e. investing so much on Technology and Communication. For examples 'Travel safe when alone', the latest campaign by the Mumbai Police to ensure women's safety in the metropolis, was launched on International Women's Day on Saturday9 Feb2014. The idea is to make sure that women who take public transport and feel unsafe can get in touch with the police by sending an SMS about their location, destination and the registration number of the vehicle to 9969977888 , a toll-free number. Soon, RTOs are also going to be asked to make sure that all taxi and autorickshaw drivers compulsorily display the toll-free number on the dashboard of their vehicles. Officers are hopeful that the initiative makes public transport more effective as they are being watched. Executive director of MTNL Piyush Agarwal said, "In the Delhi gang-rape case, the mobile phone of the victim was taken by the accused, who felt confident that doing so would ensure they don't get caught. However, now, with this initiative, even if a victim's mobile phone is taken away, police will still be able to trace her." But what If attacker take phone from victims and take out SIM card and Battery from that phone then how system will work, then this project of investing crores of rupees will not be efficient to use, so in this case SMART System will work effectively. 


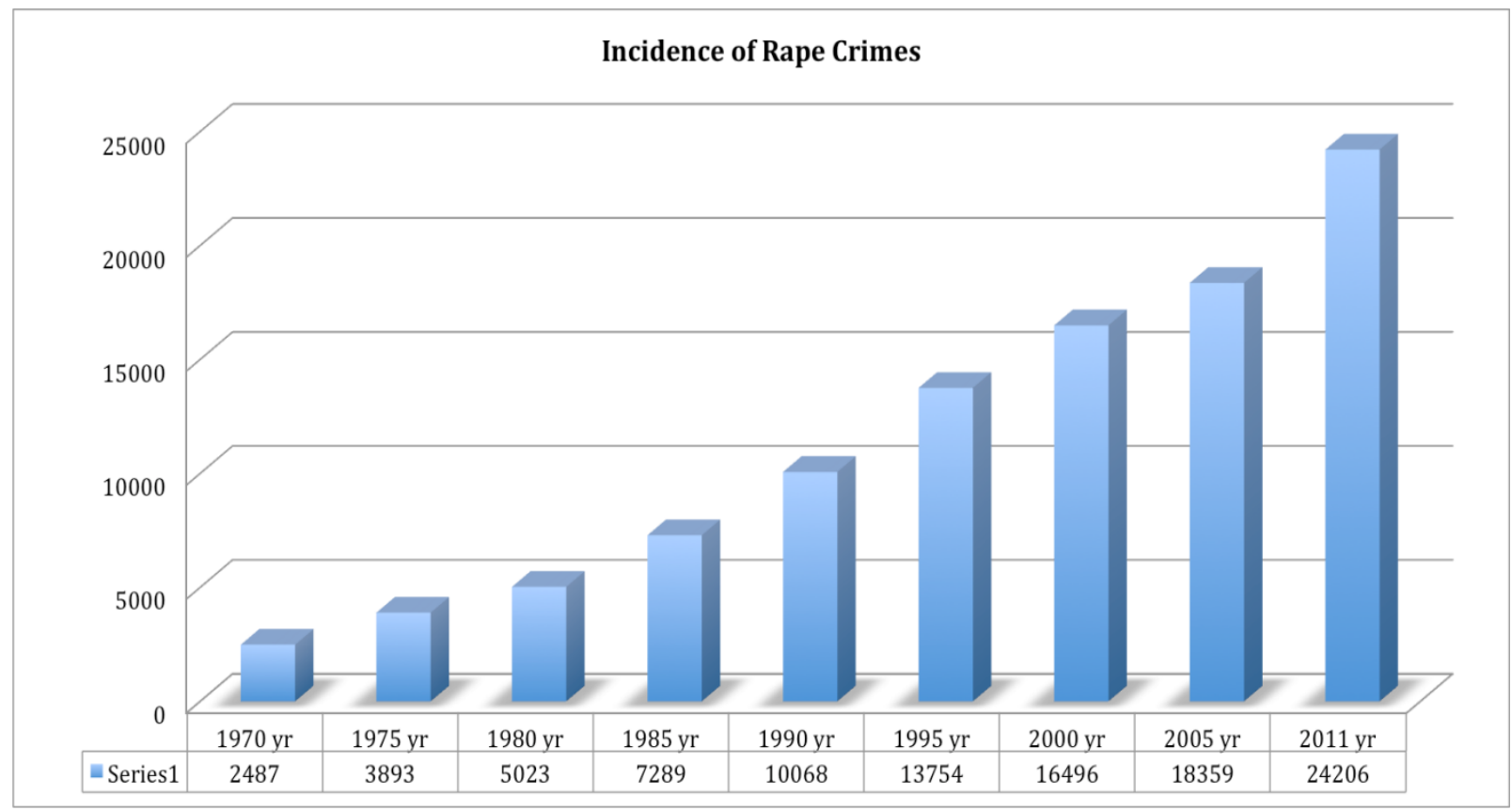

Fig. $1^{[4]}$

Diagram 1, represents the rape cases in India. It shows continuous increase in the number of rape cases reported in India. It is an astonishing figure, in 1970 the rape case ported in India was 2487 but in 2011 it is 24206 .

\section{SMART SYSTEM FOR WOMENS}

SMART system is system which will provide security from two aspects. The name SMART system is given because of two reasons

1)An App in the SMART phone. This App will work on voice recognition means App will get activated and start functioning once it gets voice of user and It will authenticate the user by taking some parameter.eg. voice pattern. If user gets authenticated then App will start functioning. For example ,Suppose a women is caught by Attacker/Raper/Thief and they snatch out the phone from that lady, at that situation this app will work

Efficiently by using techniques called voice recognition. Suppose that a lady has already set some pattern for voice recognition, say that pattern is "HELP HELP" or it could be anything which you use at critical time. So even if they have taken the phone from lady but that lady will sound "HELP HELP" loudly then this App will authenticate,If it found authenticated one ,App will start its function.

\section{SMART SYSTEM'S WORKING}

1. This App will send the message regarding the incident to set of people which is already set by victim in their phone. Along with this It will send 30 seconds audio of that incident as well as It will make the location of Victim traceable. Also it will send the message to nearest police station as well as high authority of police so that later, if lower authority of police doesn't take proper action can be punished.

2. SMART system will be specialized SMART phone in which a small battery will be fitted internally which will work only when the main battery is discharged OR Main battery is taken out from the phone. This small battery will only work for App .you will not be allowed to use small battery for other purpose. Even with this battery Screen will not visible to user i.e.. it will give user OR attacker an impression that phone is switched off or It is not working. This is the benefit of system which will not let user know that phone is working.

3. SMART system will also be special in terms of SIM card which will be by default in the phone. This SIM is like CDMA SIM card which we cannot change or cannot take out from the phone. It will be hidden. This SIM card will make the user/Phone Traceable and by using its network the Help Messages /Alert Messages and 30 seconds audio will be sent to group of specified people.

\section{ISSUES RELATED TO CURRENT SYSTEM OR APP}

All current system Apps become useless if Attacker Switched off phone or Take out battery from phone or Take out SIM card from phone.

In current system OR Apps for women security, the input from users is taken by key pressed by user of on touch Screen. But a condition where attacker snatch out phone from users and user don't get chance to press/touch that button which will cause the Apps to be activated and It will start its function.

\section{PROPOSED SYSTEM}

The proposed system will contain all the functions which are there in current system with some very important function.

1. The proposed system will work even if the attacker snatch out phone from victim and take of battery or SIM card from phone.

2. The proposed system will work by using the technique of voice recognition i.e. even though attacker snatch out phone from victim,victim don't get chance to press /touch the specified button to activate the system to perform it function but in case of SMART system the victim/user can use voice recognition technique to activate the system to perform its functions. For example user/victim can use voice pattern to get authenticated to 
system and if authenticated then it activate system to perform its basic functions.

3. User / victim can set her voice pattern say "Help. Help me", once the user speaks loudly "Help. Help me", even if the phone is not with user /victim i.e. the phone is with attacker but still voice of victim will be recognised by system and if user/victim get authenticated the event will be generated and the system will be activated to perform its functions.

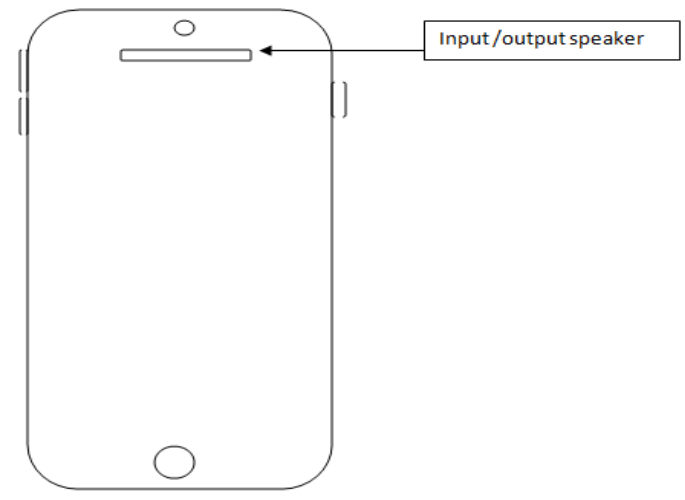

Fig. 2 Front- End of Smart Phone

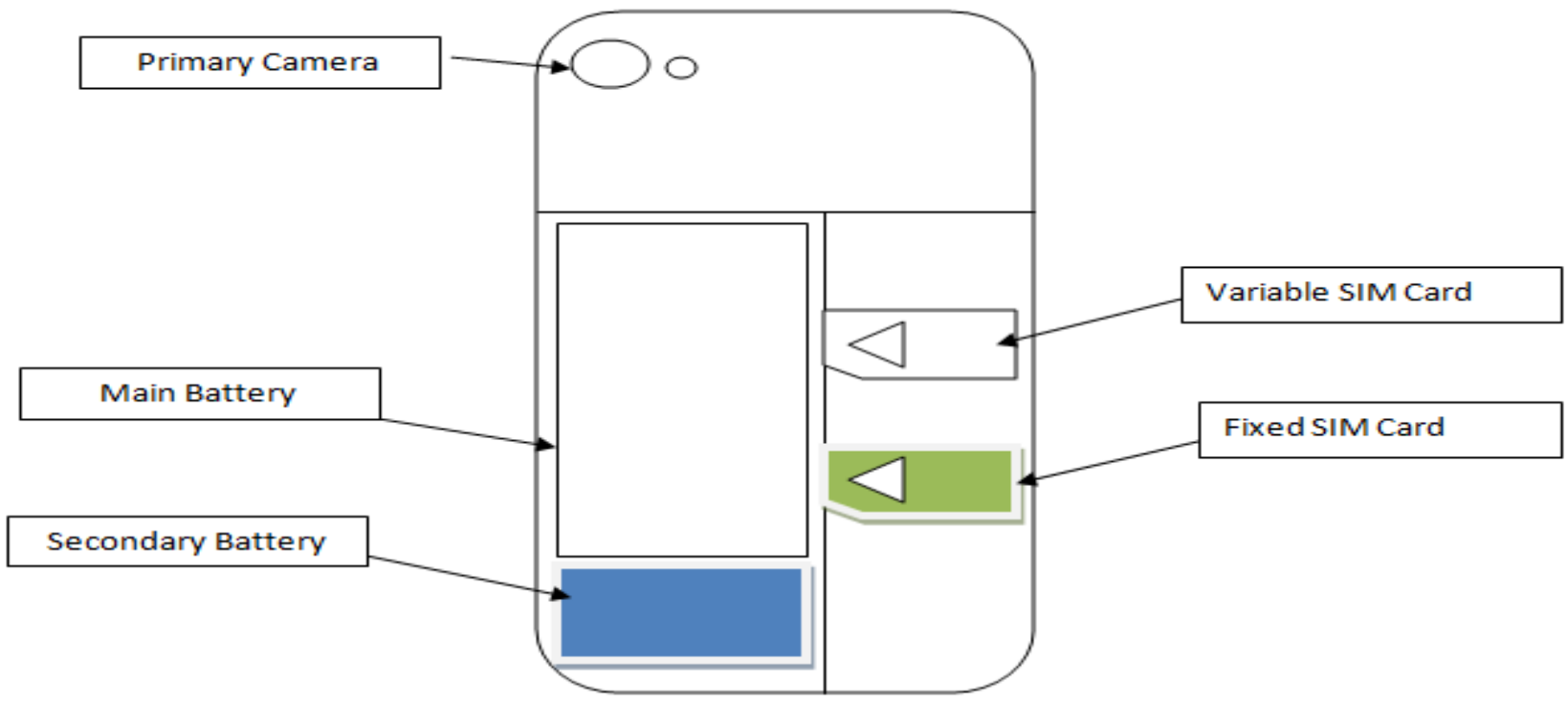

Fig. 3 Back- End of Smart Phone

In Fig. 2 the design of Smart phone can be made as per the current market demand. This will contain all the features of a smart phone as well as some extra can be added.

Fig. 3, It is back -end of smart phone. This will contain all the design which a normal smart phone has as well as secondary battery for SMART and a fixed SIM card with smart phone. It has option of variable SIM card along with a fixed SIM card which will be fixed by manufacturer only.

The Secondary Battery and Fixed SIM card will make the SMART system different from other system available. The secondary battery will help the system to be active even if the main battery is taken out or phone is switched off. This secondary memory will be used only in emergency situation i.e. when the phone is switched off /primary memory is taken out from phone. The fixed SIM card is used to send the SMS to the preferences done by the user and to inform police station.

\section{CONCLUSION}

SMART system will help to reduce the cases of sexual assault and will increase the women Security. SMART system will overcome the limitation of currently used system for women security. SMART system will be different from existing system i.e. SMART system will work even though phone is Switch off, or battery has been taken out or thrown by criminals. SMART system will make use of voice recognition technique for taking the input from user. In current system OR Apps for women security, the input from users is taken by key pressed by user on a touch Screen SMART phone. But a condition where attacker snatch out phone from users and user don't get chance to press/touch that button in that situation SMART System APP will be efficient i.e. In case of SMART system the victim/user can use voice recognition technique to activate the system to perform its functions.

\section{REFERENCES}

[1] http://crowdvoice.org/sexual-assault-in-india

[2] http://en.wikipedia.org/wiki/Rape_statistics\#cite_note-90

[3] http://www.huffingtonpost.com/siddharthchatterjee/international-womens-day_15_b_4853058.html

[4] http://upload.wikimedia.org/wikipedia/commons/7/72/Ra pe_in_India.png

[5] http://smartphoneguru.in/top-5-security-apps-for-women/

[6] http://www.thehindu.com/news/national/new-mobileapplication-for-womens-safety/article5524158.ece

[7] http://womensissues.about.com\

[8] http://timesofindia.indiatimes.com/tech/technews/Microsoft-launches-womens-safetyapp/articleshow/27968147.cms 